\title{
Sustainable restoration and long-term management of contaminated rural, urban and industrial ecosystems
}

\author{
B.J. Howard, K.G. Andersson ${ }^{1}$, N.A. Beresford, N.M.J. Crout ${ }^{2}$, J.M. Gil ${ }^{3}$, J. Hunt ${ }^{4}$, A. Liland ${ }^{5}$, \\ A. Nisbet ${ }^{6}$, D. Oughton ${ }^{7}$ and G. Voigt ${ }^{8}$
}

Centre for Ecology \& Hydrology - Merlewood, Grange-Over-Sands, Cumbria LA11 6JU, U.K.

${ }^{1}$ Riso National Laboratory, 4000 Roskilde, Denmark

${ }^{2}$ School of Life \& Environmental Science, University of Nottingham, Nottingham NG7 5RD, U.K.

${ }^{3}$ Unidad de Economia Agaria, Servico de Investigacion Agroalimentaria - DGA, Apdo. 727,

Carretera de Montanana km. 7, 50080 Zaragoza, Spain

${ }^{4}$ Centre for the Study of Environmental Change, Lancaster University, Lancaster LA1 4YT, U.K.

${ }^{5}$ Norwegian Radiation Protection Authority, P.O. Box 55, 1332 Osteras, Norway

${ }^{6}$ National Radiological Protection Board, Chilton, Didcot, Oxon OX11 ORQ, U.K.

${ }^{7}$ Agricultural University of Norway, Postbox 5026, 1432 As, Norway

${ }^{8}$ GSF Institut für Stahlenschulte, Ingolstaedter Landstrasse 1, 85764 Nueherberg, Germany

\begin{abstract}
To sustain acceptable living and working conditions in areas contaminated by radioactivity, robust and effective restoration strategies need to consider different types of environment, land use and ways of life. The allocation of resources must take account of a range of requirements to ensure sustainable use, inciuding social and ethical aspects, environmental considerations and quality of life. Current understanding of public perceptions and communication of technical information also needs to be integrated into the process so that the radiological situation is fully explained and any remediation measures are transparent to, and agreed by, affected populations. Many individual countermeasures have been developed and tested. Previously, the focus has been on evaluating their effectiveness, with some attention to cost. The current STRATEGY project aims to establish a more holistic decision framework for the selection of optimal remediation strategies for long-term sustainable management of contaminated areas. An initial step within this approach is a detailed evaluation of individual countermeasures; examples of which are provided here for an agricultural and urban countermeasure.
\end{abstract}

\section{BACKGROUND}

Following a large-scale release of radioactivity, urban, industrial and rural areas may be contaminated for many years. Consequently, areas of industrial and agricultural production, residence and recreation may all need to be managed to mitigate the impact of contamination. Emergency planning is generally focused upon the short-term response (few days - weeks) and addresses issues such as the need for evacuation, immediate problems associated with ${ }^{131} \mathrm{I}$, and requirements for restrictions on food and water. There is limited systematic consideration of long-term management to ensure sustainability of contaminated areas.

Many individual countermeasures have been developed, especially following the Chernobyl accident [1]. However, in practice many of these have only been implemented within the former Soviet Union (FSU). The applicability of most measures to other areas has not been critically assessed. Furthermore, countermeasure research has largely focused on the effectiveness of individual methods, although some attention has been given to comparative cost per unit of averted dose [2] and recent attempts have been made to consider factors affecting practicability of countermeasures such as feasibility, capacity, acceptability, and environmental side-effects [3-5]. There has been little attempt to combine these individual countermeasures within sustainable restoration strategies for contaminated areas.

In designing restoration strategies to ensure the long-term sustainability of large and varied contaminated areas, there is a requirement to adopt a more holistic approach. Resources will be limited and must be used in the most appropriate manner, considering a range of different requirements to ensure sustainable use, including social and ethical aspects, environmental considerations and quality of life. In addition, public perceptions of risk, communication of information, and the need for dialogue and consultation with affected communities, have recently become major issues when defining policy. Although these are now the subject of a substantial field of research, this has been little integrated in a 
practical context. The potentially negative social and environmental consequences of restoration must be fully considered. The implementation of a remediation strategy may lead to a reduced collective dose, but increased dose to those implementing the strategies. Thus, some measures will result in an imbalance in the distributions of dose and costs across different population groups.

\section{APPROACH}

The criteria on which we evaluate countermeasures needs to be extended from simply effectiveness and radiological protection criteria to a more integrated, holistic approach. Specifically, we need to incorporate aspects such as whether measures can be practically applied, incur considerable direct or sideeffect costs, have significant environmental side-effects, and are acceptable to society. In addition, we should explore suitable approaches for successfully communicating with a wide range of stakeholders, This is an essential step in developing a decision framework and avoiding problems previously experienced in emergency management.

The ultimate aim of our project is to construct a decision framework aiding the selection of practicable remediation strategies, to enable the long-term sustainable management of contaminated areas. As an essential first step we are identifying and extensively evaluating each measure with respect to a wide range of criteria addressing the issues described below. Within this paper, we illustrate our approach by describing the evaluation of an agricultural and an urban countermeasure.

\subsection{Practicability}

An effective countermeasure will not necessarily be suitable for use in a given contaminated area. There are many considerations which determine whether the technique can be applied, e.g.:

- is it feasible to apply in terms of available equipment and expertise, infrastructure, supply of consumables and safety equipment?

- is it applicable in the affected area, for instance can the soil be ploughed, or is it possible to applya particular method under the prevailing animal management practices?

- are large quantities of highly contaminated waste produced which are difficult to dispose of?

\subsection{Costs}

Two aspects need to be considered in cost evaluation:

- Direct costs are those associated with the implementation of the countermeasure itself and are determined by the costs of equipment purchase or hire, consumables and running costs, and labour. Whilst retrospective assessment has quantified benefits in terms of cost per unit averted dose [2], it is not possible to quantify the cost of averted dose for future accidents, since it will depend on both the extent of deposition and composition of deposition. Furthermore, it is difficult to give costs of countermeasure application in monetary terms as they will vary considerably with circumstance. Therefore, we have quantified costs in terms of requirements per unit area or animal treated, and identified influencing factors.

- Side-effect costs are a consequence of a countermeasure being applied but are not associated with the cost of application. They may include aspects such as maintenance of protected areas, endangered species, landscape, trade and human welfare. The monetary value of some side-effect costs (e.g. loss of tourism and agricultural production) can be estimated. However, for others, termed non-market goods (e.g. the loss of amenities, damage to national parks or water pollution), methodologies such as the contingent evaluation method or choice experiments are needed [6].

\subsection{Environmental aspects}

There may be secondary environmental consequences of the application of countermeasures [5] including enhanced soil erosion, removal of top soil, nutrient imbalances, reduced biodiversity, reduced agricultural productivity and water pollution. 


\subsection{Ethical aspects}

Since remediation actions may expose certain groups to risk of harm, access to information and promoting self-help strategies are important in countermeasure evaluation. Medical ethics has identified four conditions which are necessary to satisfy the requirements for free informed consent: disclosure, understanding, voluntariness and competence. These conditions dictate that those affected should be given information about possible risks and benefits together with available alternatives, that the subject should understand and agree to the treatment or research, and that the subject be mentally and physically competent to give consent. Similar considerations are appropriate to radiological protection, for instance, remediation actions may expose certain groups to risks of harm, whilst self-help strategies can be effective countermeasures. Both those people exposed as a result of their participation in remediation strategies and target groups for self-help advice need clear understandable information (i.e. disclosure and understanding), choice (voluntariness) and the ability to perform the countermeasures (competence). Our aim is to ensure that decision makers are aware of the need to consider ethical issues, to assist in their identification and to take them into account.

\subsection{Communication}

It is important to consider likely public perceptions of possible countermeasure techniques and management strategies, and the credibility and effectiveness of different public communications methods. A significant aspect of this is identification of the factors that the public consider as being relevant to the credibility of different long-term management policies. Some countermeasures which contribute to a sustainable restoration strategy may be entirely based on communication, such as education of affected communities and provision of self-help advice. Here, it is important that information sources are trusted and respected by their audiences. Crucially, communication needs to be 'two-way', that is, the preferences and concerns of affected communities need to be solicited and taken into account.

\section{APPLICATION OF APPROACH TO EXAMPLE COUNTERMEASURES}

\subsection{Administration of AFCF-boli to ruminants}

For many years it has been known that hexacyanoferrate compounds, particularly ammonium-ironhexacyanoferrate (AFCF), are effective radiocaesium binders which, if administered to animals, will significantly reduce absorption of radiocaesium in the gut. For instance, $1 \mathrm{mg} \mathrm{kg}^{-1}$ liveweight d $\mathrm{d}^{-1}$ will reduce absorption by $60 \%$ [7]. Following the Chernobyl accident, novel methods of delivering AFCF to infrequently handled animals were developed [7]. Amongst these were rumen dwelling boli, typically containing $15 \%$ AFCF and coated in wax to extend their effectiveness. The administration of three waxed boli has been shown to reduce radiocaesium contamination of sheep by c. $50-65 \%$ over a period of $9-11$ weeks [8]. Hexacyanoferrate boli have also been used in contaminated areas of the fSU. Radiocaesium binders were estimated to be the least expensive of the post-Chernobyl countermeasures used in Norway [2]. Therefore, we could conclude that AFCF-boli are an efficient countermeasure which should be used in any future accidental release of radiocaesium. Nevertheless, there are a number of shortcomings and constraints which need to be considered before boli could be used.

\subsubsection{Availability}

In Western Europe, AFCF-boli are only made by a Norwegian university, which would be incapable of supplying large quantities. The production process is not mechanised; the boli are almost entirely produced by hand. When commercial production has been attempted the boli were not effective. Whilst it is likely that given sufficient time and resources it would have been possible to develop a large-scale production facility, no further development was pursued. In the event of any future need to produce boli in large numbers, they would first need testing in controlled conditions. Use of untested boli, which proved to be ineffective, would lead to a loss of confidence. There are factories manufacturing boli in the 
fSU, however, they incorporate an alternative hexacyanoferrate compound (ferrocyn) which is less effective than AFCF and is not licensed for use in other countries.

\subsubsection{Legal constraints}

There is only temporary approval of one specific hexacyanoferrate compound within the EU [9]. The approval expires in 2001 and the likelihood of permanent approval is currently unclear. In the event of an accident, it is possible that legal constraints could be removed in an appropriate timescale, especially since boli are suitable for use in the mid to long-term after an accident.

\subsubsection{Technical factors influencing effectiveness}

Boli can be expected to achieve a c. $50 \%$ reduction in radiocaesium activity concentrations in meat and milk [8]. Therefore, if the aim of intervention is to reduce contamination to levels below the intervention limit, the initial activity concentration can be no more than twice the limit. Additionally, because most target animals for boli treatment will be free ranging, it is possible that some animals within a givell flock/herd will not be treated. To overcome this problem, it has been suggested that animals be marked as they were treated; untreated animals could then be identified [3].

The applicability of the Norwegian boli to other farming systems is not guaranteed. For instance, the standard Norwegian boli were too large to be administered to lambs in upland areas of the UK contaminated by the Chernobyl accident [10]. To produce an effective smaller boli, development (including alteration of the original formula) and testing were needed.

\subsubsection{Feasibility}

A number of veterinary products (e.g. trace minerals, wormers) are administered as boli using a dosing gun. It is likely that both the equipment (with minor adaptation) and knowledge to administer AFCF boli would be available on farms. Because they are more difficult to administer to reindeer, the use of boli has not been as high as originally anticipated in Norwegian reindeer herds [11].

\subsubsection{Side-effects}

Because AFCF contains cyanide there are obvious concerns regarding its possible toxicity. However, no effects of AFCF on animal welfare have been recorded [12]. AFCF administered to animals is excreted in faeces, which will subsequently be deposited onto soil. Uptake of ${ }^{137} \mathrm{Cs}$ by legumes and grasses was reduced by $37-51 \%$ when the soil was fertilised with manure from cows receiving AFCF [13]. No cyanide was detected in solution following $\mathrm{CaCl}_{2}$ extraction of $\mathrm{AFCF}$-treated soils [14]. Whilst some soils may contain bacteria or fungi capable of degrading cyanide, toxic levels of HCN should not arise under field conditions [5].

\subsubsection{Social and ethical considerations}

Within Chernobyl contaminated areas of the UK there was a reluctance amongst some farmers to use AFCF boli, as they perceived that this may adversely affect the "organic" image of their lamb (which could incur side-effect costs) [3]. Similarly, there has been a reluctance by some private cattle owners to use boli within the fSU [15]. It is possible that these reservations could be overcome by the provision of adequate information and liaison with farmers representatives. However, the reasons for resisting the use of boli need to be recognised as legitimate and addressed.

Undoubtedly, as with any procedure involving oral administration of comparatively large objects, there will be some fatalities. This raises animal welfare issues which need to be addressed, especially since the application of boli has no positive effect for the animal itself.

Of the four ethical criteria for free and informed consent, it is likely that disclosure, understanding and competence could be readily achieved. Voluntariness may not be as it is unlikely that an individual farmer 
will have a choice whether or not to treat his animals. However, if disclosure and understanding are effectively achieved, without giving rise to a perception of propaganda, the likelihood of farmers being willing to treat animals will be maximised; therefore the lack of choice may be mitigated.

As with many other countermeasures the administration of boli may be accompanied with compensation payments. If improperly implemented this can often lead to feelings of 'buying off'.

\subsection{Deep ploughing of parks in urban areas}

Significant external exposure can arise from contamination of parks within urban areas due to retention of y-emitting radionuclides in the top few centimetres of the soil. Deep ploughing to a depth of c. $45 \mathrm{~cm}$ using standard agricultural ploughs redistributes radionuclides within the soil profile considerably diluting the surface contamination and shielding the gamma emissions, thereby reducing external exposure by 6-10 fold [16]. The technique is simple, inexpensive, achievable on a large scale and does not create contaminated waste. However, potential shortcomings and constraints are considered below.

\subsubsection{Operational exposure}

Ploughing could be carried out by agricultural workers without the need for additional technical training, although information regarding the need for radiological safety procedures (e.g. protective clothing and respiratory equipment) would be essential. Implementation would enhance the doses received by people carrying out the procedure. Daily doses to operators which are two-three times higher than those received by people living nearby have been estimated for typical Western European urban areas [17].

\subsubsection{Environmental constraints and impact}

Soil type will affect the ability to deep plough and also the effectiveness of the technique. In particular, effectiveness is low in sandy soils. The slope of land may also limit the scope for ploughing.

Deep ploughing adversely affects soil fertility and can lead to erosion. However, the impact would be less than that of deep ploughing used as a countermeasure in agricultural systems since the extent of urban land requiring ploughing is likely to be limited and it would not be used for crop production. However, contamination will be moved closer to the water table with possible migration to groundwater.

\subsubsection{Social and ethical considerations}

Informed consent must be obtained from the people implementing the ploughing as they would receive increased doses.

Top soil removal is more effective than ploughing and removes most contamination from the area. Once, deep ploughing has been carried out, it is not possible to subsequently remove contamination. Public acceptability of diluting, rather than removing, contamination would need to be assessed, and may well vary in different communities, in relation to a number of factors including the usage of the parks (particularly by children), the destruction of biota and the aesthetic value of the landscape.

\subsubsection{Side-effect costs}

There is an obvious side-effect cost in re-establishing the park so that it can be used by the local community and there may also be losses of income by businesses associated with the park. Some sideeffect costs may need to be evaluated using the contingency or similar methods, for instance, the impossibility of re-establishing the park back to its original state with established plants.

\section{2 .5 Communication issues}

In relation to the acceptability of the countermeasure, it will be important to consult affected communities and identify preferences. Information on the perceived benefits and costs of carrying out the 
countermeasure will need to be revised in relation to the preferences of affected communities, who may well identify further costs and benefits, some probably relevant only in particular locations. This 'lay knowledge' can be highly significant in relation to the assessment of countermeasures in different areas, and its incorporation can aid effectiveness [see 4].

\section{CONCLUSION}

The above examples demonstrate that even for countermeasures which have been shown to be effective in reducing doses many factors should be carefully considered before they are implemented; some of the issues discussed will be common for many countermeasures. Once such holistic evaluations have been conducted for all reported countermeasures we will be better placed to optimise long-term restoration strategies for contaminated areas.

\section{Acknowledgements}

The STRATEGY project is being carried out under a contract (FIKR-CT-2000-00018) within the research and training programme (Euratom) in the field of nuclear energy, key action: nuclear fission and whose support is gratefully acknowledged. The paper is the sole responsibility of the authors and does not reflect Community opinion, and the Community is not responsible for any use that might be made of data appearing in this publication. We gratefully acknowledge the contributions of other STRATEGY participants.

\section{References}

[1] Howard, B.J. and Desmet, G.M. Sci. Tot. Environ. 137 (1993).

[2] Brynildsen, L.I., Selnaes, T. D., Strand, P., Hove, K., Hlth Phys. 70 (1996) 665-672.

[3] Nisbet, A.F. and Woodman, R., J. Environ. Radioact. 51 (2000) 239-254.

[4] Lepicard, S. and Dubreuil, G. H., J. Environ. Radioact. 56 (2001) 241-253.

[5] Salt, C.A., Rafferty, B., J. Environ. Radioact. 56 (2001) 99-114.

[6] Dabbert, S., Dubgaard, A., Slangen, L. and Whitby, M., The economics of landscape and wildlife conservation. (CAB International, Wallingford, 1998).

[7] Hove, K., Sci. Tot. Environ. 137 (1993) 235-248.

[8] Hansen, H.S., Hove, K. and Barvik, K., Hlth. Phys., 71, (1996) 705-712.

[9] CEC, Official Journal of the European Communities, L272 (1996) 32-35.

[10] Beresford, N.A., Hove, K., Barnett, C.L., Dodd, B.A., Fawcett, R.H. and Mayes, R.W., Small Ruminant Res., 33 (1999) 109-115.

[11] Tveten, U., Brynildsen, L. I. Amundsen, I. and Bergan, T. D. S., J. Environ. Radioact. 41 (1998) 233-255.

[12] Pearce, J. Food Chem. Toxicol. 32 (1994) 577-582.

[13] Hove, K., Strand, P. Salbu, B., Oughton, D., Astasheva, N., Sobolev, A., Valiliev, A., Ratnikov, A., Aleksakhin, R., Jigareva, T., Averin, V., Firsakova, S., Crick, M. and Richards, J. I., Use of caesium binders to reduce radiocaesium contamination of milk and meat in Belarus, Russia and Ukraine. In: Environmental impact of radioactive releases (LAEA, Vienna,1995) pp. 539-547.

[14] Vandenhove, H., van Hees M. and Vandecasteele, C., J. Environ. Radioact. 47 (2000) 149-155.

[15] Beresford, N.A., Voigt, G., Wright, S.M., Howard, B.J., Barnett, C.L., Prister, B., Balonov, M., Ratnikov, A., Travnikova, I., Gillett, A.G., Mehli, H. Skuterud, L., Lepicard, S., Semiochkina, N., Perepeliantnikova L., Goncharova N. and Arkhipov., A.N., J. Environ. Radioact. 56 (2001) 215-239.

[16] Andersson, K.G., Rantavaara, A., Roed, J., Rosén, K., Salbu, B. and Skipperud. L., A guide to countermeasures for implementation in the event of a nuclear accident affecting Nordic foodproducing areas (NKS, Roskilde, 2000).

[17] Andersson, K.G. Roed, J. Paretzke, H.G. and Tschiersch J., Modelling of the radiological impact of $a$ deposit of artificial radionuclides in inhabited areas $\mathrm{In}$ : Deposition of radionuclides, their subsequent relocation in the environment and resulting implications, Tschiersch J. Ed. (EC, Luxcmbourg, 1995) pp.83-94. 